\title{
TABAGISMO E A TRANSDISCIPLINARIDADE
}

\author{
THE TABACCO USE AND TRANSDISCIPLINARITY
}

Renata Carone Sborgia ${ }^{1}$ e Antonio Ruffino-Netto ${ }^{2}$

\begin{abstract}
'Bacharela em Letras, Bacharela em Ciências Jurídicas e Sociais-Direito. Mestranda da Faculdade de Filosofia Ciências e Letras de Ribeirão Preto-USP.'2Docente. Departamento de Medicina Social. Faculdade de Medicina de Ribeirão Preto-USP

Correspondência: renatacs@freemail.convex.com.br
\end{abstract}

Sborgia RC, Ruffino-Netto A. Tabagismo e a transdisciplinaridade. Medicina (Ribeirão Preto) 2005; 38(2): 161-163.

RESUMO: Os autores apresentam uma série de reflexões sobre o Tabagismo, chamando a atenção sobre necessidade de se efetuar estudos transdisciplinares para abordar o tema. Referem que um estudo já está em andamento, tentando levantar as crenças e valores ligados ao tabagismo entre os jovens.

Pretendem apontar caminhos para fortalecer o Programa de Controle do Tabagismo.

Descritores: Tabaco. Tabagismo. Programas de Controle. Legislação.

\section{INTRODUÇÃO}

O estudo completo do tabagismo envolve transdisciplinaridade, constituindo um excelente exercício para se pensar nas ciências, nos seus diferentes campos de atuação. Seu estudo poderá estar centrado no campo das ciências naturais abarcando aspectos da: física, química, biologia, psicologia individual. Poderá ser abordado, também, no campo das ciências culturais, envolvendo Psicologia Social, Economia, Antropologia, Sociologia, História, dentre outras áreas. Se visto pelo lado das ciências aplicadas, poderia ser estudado nos campos da Medicina, Agricultura, Ciências Farmacêuticas, Economia, Direito etc.

Tem este Ponto de Vista o objetivo de chamar a atenção sobre a necessidade de estudo, bem como, assinalar que estamos efetuando um enfoque amplo, visando a princípio levantar as crenças e valores associadas ao uso do Tabaco entre os jovens, que será objeto de publicação detalhada em breve.

\section{MAgNitUde E PERTINÊNCIA DO PRO- BLEMA}

Capez (2003) * assinala que, no mundo, os jogos e a prostituição, movimentam por ano cerca de 10 bilhões de US\$. As drogas movimentam, no mesmo período, ao redor de 100 bilhões, isto é 10 vezes mais que os jogos e a prostituição juntos. Entre as drogas lícitas, tem-se o Tabaco.

O sociólogo cubano Fernando Ortiz assinala, "com o tabaco ocorreu um dos maiores fenômenos de transculturação no mundo" (Rosemberg,2002 ${ }^{1}$ ).

* Fernando Capez- A Legislação pertinente às drogas. Conferência apresentada na 55ํㅗ SEMANA JURÍDICA DA UNAERP, 29 a 31 de Outubro de 2003, Ribeirão Preto-SP 
Quanto aos aspectos físicos, químicos e bioquímicos do tabaco, sabe-se que durante a sua combustão ou imediatamente após, 4720 substâncias diferentes foram identificadas (substâncias estas que são formadas durante a combustão ou imediatamente após a mesma ${ }^{2}$ ). Ainda, nos aspectos das ciências naturais Rosemberg $\left(2003^{3}\right)$, publica um livro, especificamente, sobre o tema nicotina, onde apresenta uma relação de 1112 referências bibliográficas.

Estima-se no mundo que haja 1 bilhão e 300 milhões de fumantes; 5 milhões de óbitos no mundo devido às doenças tabaco associadas. No Brasil, o número de fumantes seria da ordem de 30 milhões; Para o Estado de São Paulo, a estimativa é de $8 \mathrm{mi}$ hões e de 3 milhões de crianças fumantes passivas.

Para a cidade de Ribeirão Preto, as estimativas são de 115 mil fumantes, significando um percentual de $35 \%$ da população acima de 15 anos de idade. Na população entre 15 a 20 anos, seria um percentual de $15 \%$, com uma estimativa ao redor de 340 óbitos por ano atribuídos ao tabaco ${ }^{4,5,6,7}$.

Entre as patologias associadas ao tabaco, poderíamos apresentar aquelas relacionadas com os aparelhos respiratório, cardio-circulatório, digestivo e outros ${ }^{1,2,8}$. A titulo de exemplo, vamos enumerar algumas: doença pulmonar obstrutiva crônica, câncer (do pulmão, boca, esôfago, pâncreas, bexiga, rim, útero, mama e outros locais), cardiopatias isquêmicas, trombose das coronárias, lesões vasculares cerebrais, doenças vasculares periféricas, úlcera gástrica e duodenal, antecipação da menopausa nas mulheres, efeitos nocivos sobre a gravidez (deficiência ponderal e prematuridade do recém-nascido, aborto, mortalidade perinatal, complicações na gravidez, anomalias congênitas das crianças nascidas de mães fumantes), etc.

Sem dúvida alguma tabagismo significa um problema de saúde pública bastante grave e como tal, o seu controle deverá ser feito através de programas. Pereira e Ruffino-Netto $\left(2004{ }^{9}\right)$ assinalam, “ Devemos dizer, inicialmente, que não temos dúvidas a respeito da utilidade de movimentos sociais e de campanhas sanitárias visando diminuir o vício de fumar... Contudo, neste artigo, queremos alterar a perspectiva que usualmente orienta a discussão do que se convencionou chamar problema de saúde pública e, no bojo dessa alteração de perspectiva, a própria visão do tabagismo como comportamento prejudicial à saúde... Julgamos que, de fato, cabe aos trabalhadores da saúde a responsabilidade científica e social de definir o problema de saúde pública, mas compartilhando a definição com a população e, sobretudo, procurando sua participação no trabalho de remover as causas do problema..."

Visto pelo lado jurídico, sabemos que existem Leis, Códigos, Decretos, Medidas Provisórias, Resoluções... já vigentes pertinentes ao tabagismo. Destes, 20 pertencem à Legislação Federal, 12 à Legislação Estadual de São Paulo e 2 à Legislação Municipal de Ribeirão Preto.

É o caso de se perguntar: os conhecimentos científicos e jurídicos estão sendo suficientes para os Programas de Controle do Tabaco?

Visto pelo lado das ciências sociais Boltanski (citado por Minayo, $1996{ }^{10}$ ), cita "Os determinantes sociais não informam jamais o corpo de maneira imediata, através de uma ação que se exerceria diretamente sobre a ordem biológica sem a mediação do cultural que o retraduz e o transforma em regras, em obrigações, em proibições, em repulsas ou desejos, em gostos e aversões". Ou seja, o social não atua diretamente sobre o biológico. Essa atuação é sempre mediada pelo antropológico.

Tais colocações têm implicações imediatas em alguns hábitos e vícios, que ao invés de serem combatidos diretamente nos aspectos biológicos e /ou serem abordados apenas nos aspectos determinantes da supra-estrutura da sociedade, valeria a pena estudar que crenças e valores estão escondidos atrás dos mesmos. Essas foram as razões que nos levaram a estudar o problema sob um enfoque mais amplo, envolvendo a transdisciplinaridade.

À guisa de conclusão, poderíamos dizer que a definição dos problemas de saúde pública em geral, e do tabagismo em particular, não podem prescindir das crenças e valores que as pessoas têm do problema focalizado, bem como, o conhecimento destas crenças, torna-se fundamental na proposição de programas de controle do referido problema. É o que apregoamos no presente Ponto de Vista e pretendemos, tão breve quanto possível apresentar os resultados dos levantamentos que estamos efetuando. 
Sborgia RC, Ruffino-Netto A. The tabacco use and transdisciplinarity. Medicina (Ribeirão Preto) 2005; 38(2): 161-163.

Abstract: The paper presents some reflections about tobacco use and necessity of multisciplinary studies. The authors are developing study under this point of view and point out that the news focus of the study could understanding better the problem and facilitate to increase the Control Programmes of the tobacco use.

Keywords: Tobacco. Smoking. Legislation. Control Programs.

\section{REFERÊNCIAS BIBLIOGRÁFICAS}

1 - Rosemberg J. Pandemia do tabagismo - enfoques históricos e atuais. São Paulo: Secretaria da Saúde do Estado de São Paulo; 2002.

2 - Rosemberg J. Temas sobre tabagismo. São Paulo: Secretaria da Saúde do Estado de São Paulo; 1998.

3 - Rosemberg J. Nicotina-droga universal. São Paulo: Secretaria da Saúde do Estado de São Paulo; 2003.

4 - Ruffino-Netto A, Caron-Ruffino M, Passos ADC, Silva CA, Madeira NA. Tendência do tabagismo entre acadêmicos de Ribeirão Preto-SP. J Pneumologia 1988; 14:163-9.

5 - Ruffino-Netto A, Caron-Ruffino M, Passos ADC, Silva CA. Tabagismo e sintomas/doenças do aparelho respiratório entre acadêmicos ligados a área da saúde de Ribeirão Preto-SP. J Pneumologia 1989; 15: 8- 10.

6 - Ruffino-Netto A, Caron-Ruffino M, Passos ADC. Hábito de fumar entre acadêmicos ligados a área da saúde. Alguns aspectos econômicos. Medicina (Ribeirão Preto) 1989; 22:95104.
7 - Rodrigues SEM, Ruffino-Netto A. Tendência do tabagismo entre estudantes da Universidade de São Paulo, Campus de Ribeirão Preto no período de 1980-1988. Medicina (Ribeirão Preto) 1991 ; 24: 149-58.

8 - Rosemberg J. Tabagismo. Sério problema de Saúde Pública. São Paulo: ALMED/EDUSP; 1981

9 - Pereira JCM, Ruffino-Netto A. Tabagismo como problema de saúde pública. Rev Pulmão (Rio de Janeiro) 2004; 13: 69-72.

10 - Minayo MCS. O desafio do conhecimento-pesquisa qualitativa em saúde. Rio de Janeiro: Hucitec- Abrasco; 1996.

Recebido para publicação em 12/12/2004

Aprovado para publicação em 01/06/2005 